\title{
Letters
}

\section{The Reproduction Revolution-A Christian Appraisal of Sexuality, Reproductive Technologies and the Family}

Edited by John F Kilner, Paige C Cunningham and W David Hager, Grand Rapids Michigan, William B Eardmans Publishing Company, 2000, 290 pages, $\$ 20, £ 12.99$.

In their preface to this book, the editors rightly state that "few social or technological developments in history have captivated people's imagination or raised more ethical questions than today's reproduction revolution". The authors then set that revolution in a wider context from which it is all too easily divorced today, namely the nature and meaning of sexuality and the fundamental importance of the family. As a "Christian appraisal" it is a useful apologia pro vita sua for those of us who share this credo. It also sets down a clear and consistent ethical position for all interested in the field.

It never pretends that the issues are simple and straightforward. I, for example, empathised strongly with William Cutrer's "physician's perspective": "we all need to listen, to think, to analyze and to pray for wisdom and discernment as we struggle with these issues". In his chapter, A child of one's own: at what price, Gilbert Meilander argues that our headlong pursuit of technology and commercial gain has "fashioned a world in which we regularly create moral conundrums that are beyond our ability not only to solve but even to name".

Among the fundamental issues that are dealt with are the nature and meaning of sex and the consequences of separating sex and reproduction; there is a key chapter on the moral status of embryos. At the end of the book, Charles Sell powerfully affirms the family and a strong commitment to marriage as the bedrock of intimate and compassionate communities. Here and elsewhere there is recognition of the importance of strong genetic ties and kinship within society. Among the practical issues dealt with in depth are hormonal contraception, using donor eggs and sperm, surrogacy and human cloning. We are reminded on several occasions of the subtle but significant shift from use of the word "procreation" to "reproduction". The editors state that this "embodies a fundamental shift from the implicitly God-honoring term (procreation) to the human-centered manufacturing language of production".

As an obstetrician and gynaecologist I am greatly concerned by the seeming conspiracy of silence on the profoundly deleterious effects of the contemporary understanding and commercialisation of sex among our young people as nothing more than a means of self gratification. The true underlying causes of the havoc consequent on the current epidemic of sexually transmitted diseases (particularly chlamydia trachomatis) and high rates of teenage pregnancy are not only being ignored but are deemed to be inadmissible. These issues are dealt with from the American perspective in chapters on the casualties of the sexual revolution and sexually transmitted diseases. We badly need to heed these messages.

In his chapter, The hidden plaintiff, Martin Palmer brings home the importance of having a touchstone we can employ to assist us in knowing what we should do when faced with moral decisions. He quotes the late $\mathrm{Dr}$ Jerome Lejeune who, in 1993, reminded us that there was such a touchstone which, "if the politicians remember it, they can make honest laws; if the technicians do not forget it, technology will remain the honest servant of humanity.-This phrasejudges everything and forever. It just says: 'What you have done unto the smallest of Mine, you have done it unto Me'." Not everyone reading this will be able to affirm the specifically Christian reference in that statement but it remains a fundamental principle that speaks to our shared humanity whatever our beliefs or world-view.

GORDON M STIRRAT Centre for Ethics in Medicine, University of Bristol

\section{Pure Selection: The Ethics Of Pre-Implantation Genetic Diagnosis And Choosing Children Without Abortion}

Christian Munthe, Göteborg, Acta Universitatis Gothoburgensis, 1999, 310 pages, 180 Kroner.

This book investigates the issue of "pure selection"-that is, choosing the genetic characteristics of one's children, without using abortion as the method to achieve this. Pure selection is made possible by the relatively new technology of preimplantation genetic diagnosis (PGD), in conjunction with now-routine IVF procedures for creating embryos. In PGD, a cell or cells can be extracted from an early embryo, and be subjected to genetic diagnosis of whatever kind, without damaging the embryo. So embryos with the genetic make up favoured by the parents-to-be can be identified and transferred to the uterus, whilst those with non-favoured genetic make up can be discarded. Hence choice about the genetic characteristics of children is achieved without recourse to invasive procedures for prenatal diagnosis, 
and without termination of pregnancy, which is not only physically invasive, but also ethically controversial.

The author firstly presents a case study of the events involved in the introduction of PGD into clinical practice in Sweden, and then proceeds to a thorough, at times almost too thorough, examination of the ethica arguments for and against use of PGD for pure selection. From the broad ground covered in this book, I want to pick one issue which I find to be of particular interest. This is the central moral question of whether there is anything morally wrong with discarding embryos which are not selected.

As Munthe points out, PGD is only preferable to selective abortion as a method of selection if the disposal of unwanted embryos is ethically neutral, or at least less problematic than abortion of a fetus. It is often simply assumed that this is so, but Munthe challenges the reader to seek an argument for it. Interestingly, he considers in detail not the Catholic-style objection to embryo destruction (namely, that the embryo is morally a person from the moment of conception), but possible utilitarian objections. The most significant fact about both embryos and fetuses, from a utilitarian point of view, is the consequence of destroying them, namely that a person's life has been prevented from existing. Hence, except in the case of the most severe genetic disease in which the life would consist of more suffering than happiness, a significan amount of utility has been lost. Moreover, as Munthe observes, PGD typically involves the destruction of severa embryos, whereas abortion involves only one fetus-and the numbers always count for utilitarians. So are utilitarians logically required to object to pure selection using PGD?

Munthe advances several arguments to show that this is not necessarily so, the most compelling of which is the replaceability argumentthat the lost life of the discarded embryo will be replaced by the life produced by the embryo selected for, and that replacement life will have more happiness than the lost life, even if only by a relatively small margin. But he also explores the fundamental problem of the utilitarian approach to the value of future lives. The utilitarian seems left with the unpalatable choice between, on the one hand, saying there is an obligation to create more and more people whose lives will be only marginally better than no life at al (Parfit's repugnant conclusion), or on the other hand, allowing that the only harms that matter are those done to already existing people, which means there is nothing wrong with deliberately bringing into the world a child with a significant disability (since that child would otherwise never have existed at all, and is not harmed by its coming into existence). This is Parfit's non-identity problem. Munthe's preferred solution is to opt for the repugnant conclusion, although, frustratingly, he does not give an argument for this preference.

This utilitarian approach to the moral evaluation of embryo destruction in pure selection is, in my view, a central feature of this book. My one criticism would be that Munthe does not highlight this enough, but rather presents a whole range of possible arguments for and against PGD for pure selection, apparently giving all of them equal weight, when some are clearly much more to the point than others. On the other hand, the book certainly does provide a thorough overview of the ethical issues associated with PGD, and would be an excellent starting point for anyone wishing to gain an efficient grasp of the area. The broad coverage of a range of issues means that each one cannot be pursued in as much depth as readers more familiar with the issues might like, but, in all fairness, the book cannot be expected to provide both.

LYNN GILLAM University of Melbourne and Murdoch Childrens Research Institute

\section{Designer Myths: The Science, Law and Ethics of Preimplantation Genetic Diagnosis}

Kay Chung, London, Progress Educational Trust, 1999, 23 pages, $£ 5.00$.

This booklet is the first in a series of publications called Briefings in Bioethics by the Progress Educational Trust (PET) charity. Funding from the Department of Health has facilitated the series, which aims to cover a range of ethical issues in biomedicine. Designer Myths is written by the trust's communications officer, Kay Chung, and examines the scientific, legal and ethical issues arising from preimplantation genetic diagnosis (PGD).

With advances in the ability to test for a growing number of specific genetic diagnoses and developments of new reproductive technologies, PGD (whilst still technically difficult) is now a real possibility for some families who previously had to rely on fate or forgo having children. Preimplantation genetic diagnosis allows testing of the fertilised egg for specific genetic diagnoses, so that only unaffected fetuses are implanted and prenatal diagnosis can be avoided.

The bulk of the 23-page booklet discusses the science and technical aspects of PGD, including details of the treatment cycle and current success rates. The law regarding PGD is discussed mainly in the context of UK law, but the situation in the rest of the world is also covered. The ethics of PGD are covered in three sections. The status of the human embryo section lays out the ethical difficulties that those who believe that life begins with fertilisation have with PGD.

The belief of some that PGD constitutes a form of eugenics is examined and counterargued with the availability of abortion in general and with the fact that PGD will only ever be an option in a small percentage of all congenital abnormalities. The fear that such technologies will spin out of control is explored in the slippery slope section. Such worries are largely dismissed on the basis that there are currently too many technical and practical obstacles for the "designer baby" to become a reality. The booklet ends with a discussion of current policy issues and makes some practical recommendations on future policy and funding issues.

The booklet offers a concise and clearly laid out discussion of the practical, scientific, ethical and social aspects of PGD. It is aimed at both professionals and lay people and I would imagine that the latter especially would find this an informative, easy to read publication. In 23 pages, in-depth ethical arguments are clearly not possible but most of the arguments and counterarguments for PGD are aired. Since PET is an organisation which "promotes the benefits of reproductive and genetic technologies", the monograph does clearly have a conclusion in favour of PGD but it is not biased.

DR ANNEKE LUCASSEN

Consultant/Senior Lecturer in Clinical Genetics, The Princess Anne Hospital, Southampton 